\title{
The phytotron of the Institute for Horticultural Plant Breeding (IVT), Wageningen, the Netherlands. A revision of previous descriptions
}

\section{Smeets}

Institute for Horticultural Plant Breeding (IVT), Wageningen, the Netherlands

Key words: Phytotron, controlled environment

\section{Summary}

A new description is given of the phytotron of the Institute for Horticultural Plant Breeding (IVT), Wageningen, the Netherlands.

\section{Introduction}

A phytotron may be defined as a laboratory in which the effect of environmental factors, mainly temperature and light, on the growth and development of plants can be studied. The IVT phytotron (Fig. 1), which was put into operation in the spring of 1953, was one of the first phytotrons in Europe. Since the first description was published (Braak \& Smeets, 1956) the equipment has been continuously improved, so that the first description and the one published later (Smeets \& Braak, 1962) are out of date. A new description is presented in this paper. Data on the accuracy of the environmental control will be published elsewhere.

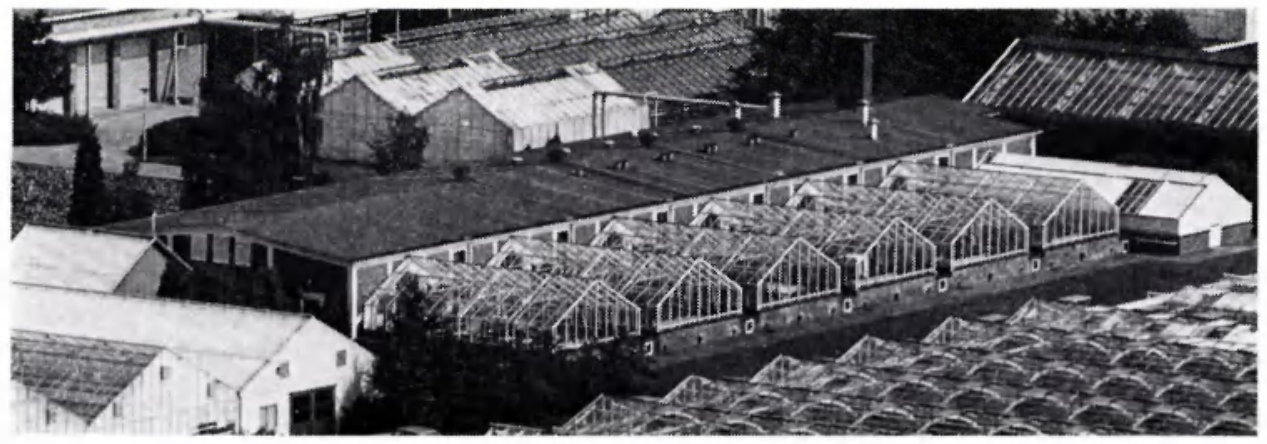

Fig. 1. Rear view of the IVT phytotron. 


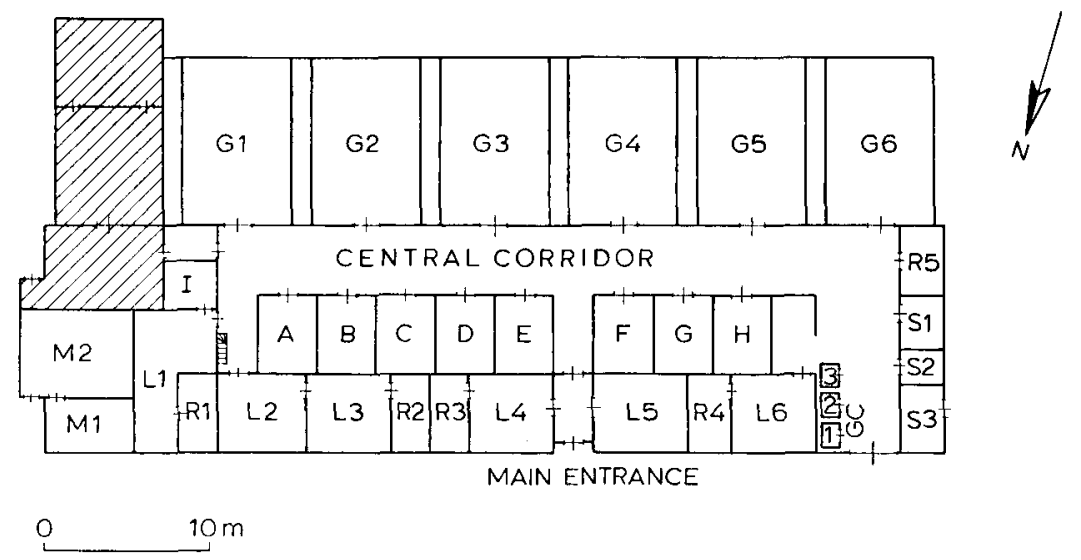

Fig. 2. Ground plan of the IVT phytotron. The hatched part does not belong to the phytotron proper.

\section{General design}

Fig. 2 shows the ground plan of the IVT phytotron. At the south side of the building, along a central corridor, 6 glasshouses (G1-G6) are situated in which both temperature and air humidity are controlled. The houses are kept at constant temperatures of $10,14,17,20,23$ and $26^{\circ} \mathrm{C}$, respectively, throughout the year. The air humidity is held at $70 \%$. On the other side of the corridor 8 growth rooms (A-H) are located. In the rooms A-E temperature can be controlled between -10 and $+25{ }^{\circ} \mathrm{C}$, in $\mathrm{F}, \mathrm{G}, \mathrm{H}$ between +10 and $+40{ }^{\circ} \mathrm{C}$. Light intensities up to $75 \mathrm{~W} / \mathrm{m}^{2}$ are possible in A-E, in $\mathrm{F}, \mathrm{G}, \mathrm{H}$ the maximum possible light intensity is $18 \mathrm{~W} / \mathrm{m}^{2}$. In all rooms air humidity can be controlled between 50 and $95 \%$.

For culture of plants in vitro an air-cooled room (I) with artificial light and 3 prefab growth cabinets (GC1-3), each with a capacity of $1.5 \mathrm{~m}^{3}$, are available. In these cabinets the temperature can be controlled between +10 and $+40{ }^{\circ} \mathrm{C}$ and the air humidity between 50 and $95 \%$. Light intensities up to $50 \mathrm{~W} / \mathrm{m}^{2}$ are possible.

On the north side of the building are the working rooms (R1-R4) and laboratory rooms (L1-L6) for the staff, on the west side the sanitary conveniences (S1-S3) and a room (R5) for the gardeners tending the experimental plants.

Heating is effected by hot water from gas-fired boilers situated in a central boiler house in the experimental garden of the Institute. The hot water enters the building on the east side through room M1 in which the circulating pumps are located. The adjacent room M2 contains the pumps for the water supply. Cooling is effected by refrigerating compressors operating with freon-12. Each glasshouse and growth room has its own compressor. In the basement below L1 and R1 are the compressors for the growth rooms A-E and the glasshouses G1-G3. Those for the growth rooms $F, G, H$ are on the ceiling above these rooms, and those for the glasshouses G4-G6 on the ceiling above R5 and S1-S3. 


\section{The glasshouses}

All 6 glasshouses are $10 \mathrm{~m}$ long, $6 \mathrm{~m}$ wide and $3.6 \mathrm{~m}$ high. Along both sides and at the end there are fixed benches. The remaining space can be used for placing trucks or a bench. To admit as much light as possible into the houses the rafters are thin and the glass panes large.

Fig. 3 shows a cross section of one of the glasshouses. Under the rear bench a cooler and a heater $(\mathrm{C}+\mathrm{H})$ are fitted, with a ventilator on both sides (V1, V2). The air in the glasshouse is passed over the cooler and the heater by the ventilators and is either cooled or heated and subsequently blown under the side benches which are closed with perforated plates. Through these perforations and through the space between the side benches and the glass the air returns to the glasshouse.

In the outer wall, at the side of the rear bench, there are 3 adjustable openings, one below the rear bench and one below each side bench. Through the opening under the rear bench outside air is introduced and through the other two openings inside air is removed.

In the centre of each glasshouse, $1.2 \mathrm{~m}$ above the floor, a thermostat $(\mathrm{T})$ and a hygrostat $(\mathrm{H})$ are fitted in a white painted box which is ventilated continuously.

When the temperature falls below the value set on the thermostat, hot water starts to circulate through the heater. The amount of circulating hot water depends on the decline in temperature. When the temperature rises above the set value, the air is cooled.

Two spray nozzles are fitted below each side bench to humidify the air. When the humidity falls below the value set on the hygrostat, the sprayers are activated. When the humidity rises above the pre-established setting, the cooler is put in operation. As a result the excess of moisture is deposited on the cooler as water or ice.

Daylight can be intensified or lengthened by artificial light. For high-intensity illumination high-pressure mercury-vapour lamps HPL-N $400 \mathrm{~W}$ are used. In each house 20 lamps can be operated. To lengthen the day with low light intensities
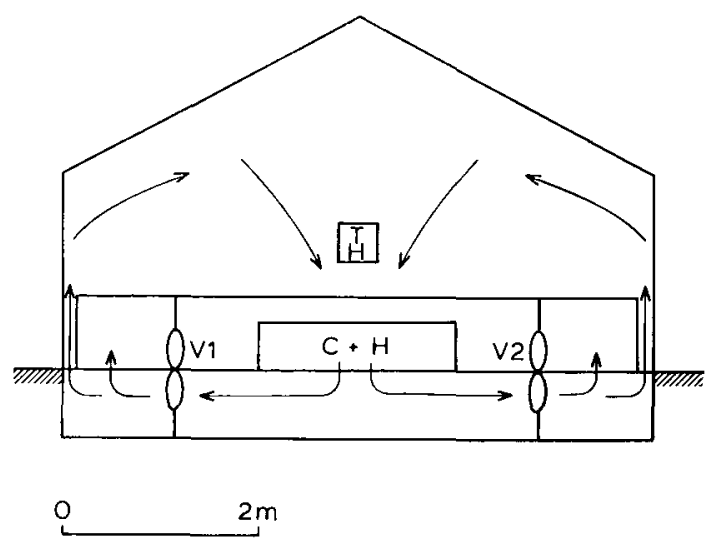

Fig. 3. Cross section of one of the glasshouses G1-G6.

Neth. J. agric. Sci. 26 (1978) 
incandescent lamps can be used. The duration of illumination is controlled by electrically operated time switches.

\section{The growth rooms}

The growth rooms $\mathrm{A}-\mathrm{E}$ are $5 \mathrm{~m}$ long, $3 \mathrm{~m}$ wide and $2.5 \mathrm{~m}$ high. The walls and the ceiling are insulated with cork. Fig. 4 shows a longitudinal and a cross section of one of these rooms. Under the floor is an air duct in which are fitted a ventilator (V), a heater (H1), a sprayer (S), a cooler (C) and a second heater (H2). The ventilator blows the air into the room through a perforated plate located along one of the side walls. The air is exhausted on the opposite side of the room through a similar perforated plate. Outside air is introduced through P1 and inside air is removed through $P 2$. The amounts are regulated by hand-operated dampers (D1, D2).

Each growth room is fitted with 2 thermostats (Ts), one controlling the day and the other the night temperature. The duration of both temperatures is regulated by an electric time switch. The cooler is activated when the temperature is too high, the heater when it is too low.

Air humidity is controlled hygrostatically $(\mathrm{H})$. When the humidity is too low, the air is humified by the sprayer. Simultaneously the heater $\mathrm{H} 1$ is put into operation to improve the evaporation of the water. When the humidity is too high, the heater $\mathrm{H} 2$ is switched on automatically, the temperature rises and the cooler is turned on. The excess of water either condenses or turns to ice on the cooler.

The artificial light consists of mercury light and, to improve its spectral composition, of incandescent light. Each room is fitted with 16 high-pressure mercuryvapour lamps HPL-N $400 \mathrm{~W}, 8$ high-pressure mercury-vapour lamps HPL $700 \mathrm{~W}$ and 16 incandescent lamps of $200 \mathrm{~W}$. The lamps (L) are located above two glass windows in the ceiling of the room. When the lamps are burning, cold water runs over the glass panes. To suppress the growth of algae in the water, ultraviolet lamps
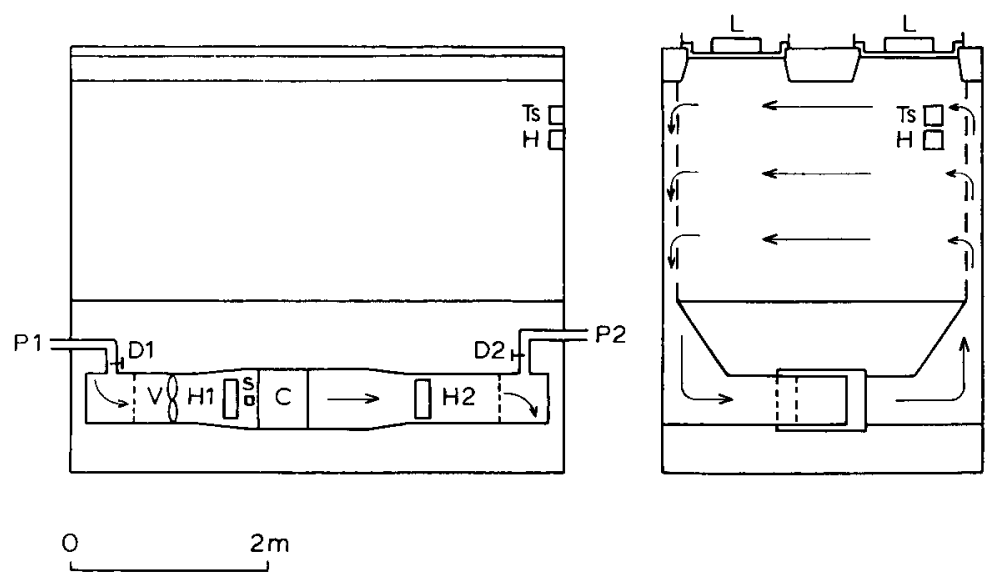

Fig. 4. Longitudinal and cross section of one of the growth rooms A-E. 

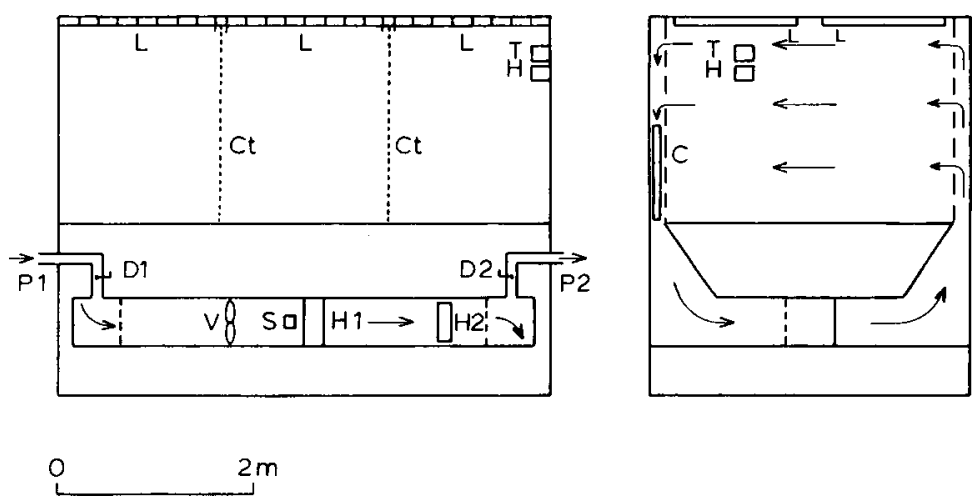

Fig. 5. Longitudinal and cross section of one of the growth rooms $F, G, H$.

are fitted along the glass panes. To enable the incandescent light to be also used independently of the mercury light, the duration of both can be controlled separately.

The growth rooms $\mathrm{F}, \mathrm{G}$ and $\mathrm{H}$ are each $5 \mathrm{~m}$ long, $3 \mathrm{~m}$ wide and $2 \mathrm{~m}$ high. Here too the walls and the ceiling are insulated with cork. Fig. 5 shows a longitudinal and a cross section of one of these rooms. The air circulation system is the same as in the rooms A-E. In an air duct under the floor are a ventilator (V), a sprayer (S) and 2 heaters ( $\mathrm{H} 1$, and a reheater $\mathrm{H} 2$ ). The cooler $(\mathrm{C})$ is situated behind the perforated plate where the air in the room is exhausted.

The temperature is controlled by a thermostat $(T)$ operating the cooler and the heaters.

Air humidity is controlled by a hygrostat $(\mathrm{H})$ which puts the sprayer in operation when the humidity is too low or the cooler when the humidity is too high.

On the ceiling of each room 48 fluorescent tubes TLF 40 W/34 De Luxe (L) are fitted. Each room can be divided into 3 compartments by means of curtains $(\mathrm{Ct})$. The duration of illumination can be controlled separately in each of the compartments.

\section{References}

Braak, J. P. \& L. Smeets, 1956. The phytotron of the Institute of Horticultural Plant Breeding at Wageningen, Netherlands. Euphytica 5: 205-221.

Smeets, L. \& J. P. Braak, 1962. Das Ventilationssystem der Klimagewächshäuser im Phytotron des Instituts für Gärtnerische Pflanzenzüchtung, Wageningen, Niederlande. In: R. Knapp (Ed.), Untersuchung der Pflanzen - Entwicklung unter klimatisch kontrollierten Bedingungen. Einrichtungen und Arbeitsergebnisse in Phytotronen, klimatisierten Gewächshäusern, Klimakammern und ähnlichen Anlagen. Eugen Ulmer, Stuttgart, p. 7-11. 